\title{
Mass Spectrometric Study of the Effects of Hydrophobic Surface Chemistry and Morphology on the Digestion of Surface-Bound Proteins
}

\author{
Alan Doucette, David Craft, and Liang Li \\ Department of Chemistry, University of Alberta, Edmonton, Alberta, Canada
}

\begin{abstract}
Our previous work has demonstrated that reversed-phase chromatographic micro-beads can be used to capture proteins from complex biological matrices and the surface-bound proteins can be enzymatically digested for protein identification by mass spectrometry (MS). Here we examine the peptides generated from digestion of proteins bound to various types of micro-bead surfaces in order to determine the effects of surface chemistry and surface morphology on the digestion process. Detailed examinations of site cleavages and sequence coverage are carried out for a tryptic digestion of cytochrome $c$ adsorbed on reversed-phase polystyrene divinylbenzene (Poros $\mathrm{R} 2$ beads) versus $\mathrm{C}_{18}$ bonded-phase silica beads. It is shown that although the surface does not completely hinder the digestion of cleavage sites of the protein, the digestion products are clearly different than those obtained from a solution digest. Specifically, a partial digestion results from surface digestion, resulting in a greater number of missed cleavages than a comparable solution digest. Subsequent comparisons of peptide mass maps generated from the digestion of various proteins on surfaces with altering chemistry $\left(\mathrm{C}_{4}\right.$, $\mathrm{C}_{8}, \mathrm{C}_{18}$, and $\mathrm{R} 2$ beads), or with different surface morphology, were performed. The results reveal that surface chemistry plays only a minor role in affecting the peptide mass maps, and surface morphology had no noticeable effects on the resulting peptide mass maps. It is also shown that the mass spectrometric detection method used to analyze the digested peptides can significantly influence the information content on cleavage sites and the extent of sequence coverage. The use of a combination of MALDI, LC/off-line MALDI, and LC/ESI MS is demonstrated to be crucial in revealing subtle changes in the peptide mass maps. (J Am Soc Mass Spectrom 2003, 14, 203-214) @ 2003 American Society for Mass Spectrometry
\end{abstract}

$\mathrm{T}$ There has been a long-standing interest in performing enzymatic digestion of proteins while the sample is bound to a surface or substrate for the purpose of protein identification by either Edman sequencing or by mass spectrometry (MS). For example, protease digestion of proteins electroblotted onto nitrocellulose was demonstrated by Aebersold et al. in 1987 [1]. In a more recent application, endoprotease digestion of surface-bound proteins has been applied to the technique of surface-enhanced laser desorption ionization (SELDI) MS [2-4]. The SELDI technique involves the use of surfaces with various functional activities to capture target proteins. Following protein capture, endoprotease digestion can be directly performed in situ, with the resulting peptides analyzed by MS. In our previous work, we have demonstrated the utility of a protein-digestion protocol involving an initial capture

Published online January 27, 2003

Address reprint requests to Dr. L. Li, Department of Chemistry, E3-44 Chemistry Building, University of Alberta, Edmonton, Alberta T6G 2G2, Canada. E-mail: liang.li@ualberta.ca of proteins onto reversed-phase (hydrophobic) chromatography beads, followed by tryptic digestion of the bound protein for MS analysis [5-7]. Our research goal is to develop an integrated system for automated protein sample cleanup, preconcentration, digestion, and subsequent MS analysis of the digestion products for protein identification. Although our earlier results reveal that surface-bound proteins will undergo enzymatic cleavage, the specific effects of protein adsorption, surface chemistry, and morphology on the digestion process have not yet been explored.

Considering that protein sequence information obtained by MS is strongly dependent on the extent of protein digestion, understanding the digestion process of surface-bound proteins is clearly important in developing an effective protein identification and characterization method involving surface digestion. However, to our knowledge, there has been no systematic investigation on the effects of varying hydrophobic surface chemistry and morphology on the digestion of surfacebound proteins. Although a number of reports have demonstrated the feasibility of digesting proteins while 
bound to various types of membrane surfaces [1, 8-17], there are conflicting results on the extent of proteolysis that has been observed on membranes. For example, Scleuder et al. reported on their digestion results using hydrophobic versus hydrophilic membranes in the form of modified or unmodified polyvinylidene fluoride (PVDF), concluding that superior peptide mass fingerprints can be obtained using a hydrophilic membrane [14]. It was shown that the digestion results on hydrophobic membranes were poor, providing irreproducibly positive results at best. In another report, however, Bienvenut et al. observed that in situ digestion on a hydrophobic membrane generates similar peptide mass maps as those obtained from in-gel digestion [9]. These conflicting results may well reflect the differences in experimental conditions used for digestion of membrane-bound proteins.

For our bead-digestion application [5-7], the experimental conditions used are quite different from those described in the above mentioned reports. An intuitive consequence of protein adsorption to a hydrophobic bead surface is that interactions between the protein and surface may lead to inaccessibility of the enzyme to cleave certain digestion sites of the protein. Supporting evidence for this was given by Aguilar et al., who found that for a protein adsorbed to reversed-phase bonded silica, only those sites exposed to the solvent were accessible to proteolysis [18]. They reported that a tryptic digestion of cytochrome $c$ adsorbed to reversedphase $\mathrm{C}_{18}$ beads was blocked at certain amino acid residues that correspond to regions of protein contact with the surface. In some related work, proteins bound to antibodies have been digested with enzymes as a means of mapping epitopes [19-21]. Chemical modification of free versus antibody-bound proteins has also been used to study protein binding sites [22]. It has been shown that the rate of enzymatic cleavage or chemical reactivity for a protein complex is reduced, most significantly at regions where the protein is in contact with the antibody (the epitope). Similarly, our previous results on biotinated proteins complexed to avidin coated beads revealed that such interactions prevented efficient trypsin digestion [23, 24]. However, these interactions are quite different from those that are experienced by a protein adsorbed to a hydrophobic surface.

There were also reports indicating that the interactions between a protein and a surface may improve the overall digestion efficiency. Litborn et al. observed an increase in the digestion efficiency for protein samples contained in nanovials and hypothesized that the high surface-to-volume ratio of the nanovials helped to promote surface-induced protein denaturation [25]. In Aguilar's report on the digestion of proteins on $\mathrm{a} \mathrm{C}_{18}$, it was also suggested that conformational changes could result in certain residues becoming increasingly accessible, thereby increasing digestion efficiency at these sites [18]. Guillochon and co-workers made use of a surface digestion protocol to generate unique peptide fragments of hemoglobin through chymotryptic and V8 protease hydrolysis of the protein adsorbed on an anionic resin $[26,27]$.

In this work, we present our studies on the digestion characteristics of surface-bound proteins. In particular, the digestion of a protein on different types of hydrophobic supports is explored. Optimal conditions for digestion of adsorbed proteins on these surfaces are therefore determined. In addition, we demonstrate that using a combination of direct matrix-assisted laser desorption ionization (MALDI), liquid chromatography (LC)/off-line MALDI, and LC/electrospray ionization (ESI) MS analysis, instead of using a single MS detection technique by itself, subtle changes in protein digestion characteristics can be revealed.

\section{Experimental}

\section{Materials and Reagents}

The proteins used in this study, including the enzyme trypsin (from bovine pancreas, TPCK treated to reduce chymotrypsin activity; dialyzed, lyophilized) were from Sigma Aldrich Canada (Oakville, Ontario, Canada). Poros $20 \mathrm{R} 2$ beads $(20 \mu \mathrm{m})$ were from PerSeptive Biosystems (a gift of Professor F. Cantwell, University of Alberta). PRP-3 (12-20 $\mu \mathrm{m})$, PRP-1 (12-20 $\mu \mathrm{m})$, and PRP-Infinity $(4 \mu \mathrm{m})$ beads were purchased from Hamilton Company (Reno, NV). Reversed-phase $\mathrm{C}_{18}, \mathrm{C}_{8}$, and $\mathrm{C}_{4}$ bonded-phase silica beads $(20-30 \mu \mathrm{m})$ were from Vydac (Hesperia, CA). The 1-200 $\mu \mathrm{L}$ Micro capillary Tips (gel loader tips) were purchased from Rose Scientific (Edmonton, Alberta, Canada). The glass micro-fiber filters were from Whatman (Maidstone, UK). A BioRad protein assay kit based on the Bradford Protein Assay was used to quantify the amount of protein in solution. Analytical grade acetone, methanol, acetonitrile, acetic acid, and trifluoroacetic acid (TFA) were from Caledon Laboratories (Edmonton, Alberta, Canada). Water used in the experiments was from a NANOpure water system (Barnstead/Thermolyne, Dubuque, Iowa). All other chemicals were purchased from Sigma Aldrich Canada.

\section{Digestion of Cytochrome c Adsorbed on Micro-Beads}

Poros R2 beads or Vydac $C_{18}$ silica beads were saturated with cytochrome $c$ and subjected to tryptic digestion using a procedure similar to that described by Aguilar et al. [18]. The beads $(7.5 \mathrm{mg})$ were first washed in methanol and then in 35\% acetonitrile/water and gently shaken for $2 \mathrm{~h}$ in a $500 \mu \mathrm{L}$ solution of $7.5 \mathrm{mg} / \mathrm{mL}$ cytochrome $c$. Following this, the beads were washed with four changes of enzyme buffer $\left(50 \mathrm{mM} \mathrm{NH}_{4} \mathrm{HCO}_{3}\right.$ containing $2 \mathrm{mM} \mathrm{CaCl} 2$ ). The beads were incubated with shaking in $0.5 \mathrm{~mL}$ of enzyme buffer containing 75 $\mu \mathrm{g}$ of trypsin for $20 \mathrm{~h}$ at $37^{\circ} \mathrm{C}$. The reaction was terminated with 2 drops of $2 \mathrm{M} \mathrm{HCl}$ and the supernatant was retained. The beads were then eluted with 250 
$\mu \mathrm{L}$ each of 25,50 , and $75 \%$ acetonitrile/water containing $0.1 \%$ TFA, pooling the extracts prior to analysis. 1 $\mu \mathrm{L}$ portions of the supernatant and of the extract were reserved for MALDI analysis. The supernatant and extracts were combined and concentrated by solvent evaporation with a Savant SpeedVac Concentrator (Fisher Scientific, Ottawa, Ontario, Canada) to a final volume of approximately $200 \mu \mathrm{L}$. The sample was then subjected to HPLC fractionation and analysis.

\section{Solution Digestion of Protein}

A $10 \mu \mathrm{L}$ protein sample, at a concentration of $1 \mu \mathrm{g} / \mu \mathrm{L}$, was buffered with $1 \mu \mathrm{L}$ of $1 \mathrm{M} \mathrm{NH}_{4} \mathrm{HCO}_{3}$ and digested using $1 \mu \mathrm{L}$ of $1 \mu \mathrm{g} / \mu \mathrm{L}$ trypsin. The solution was incubated at $37^{\circ} \mathrm{C}$ for $2 \mathrm{~h}$. The digestion was stopped by acidifying the solution with $10 \%$ TFA.

\section{Protein Digestion in Micro-Columns}

The design of the micro-column is based on work presented by Roepstorff and co-workers [28] and by Annan et al. [29]. Briefly, the column is formed from a Micro capillary gel loader tip $(1-200 \mu \mathrm{L})$, which had been pinched at its end with pliers. A piece of glass micro-fiber membrane formed a frit in the micro-columns. The columns were packed with micro-bead resin by transferring an aliquot of the resin, suspended in methanol at a concentration of $10 \mathrm{mg} / \mathrm{mL}$, to the gel loader tip. The procedure for sample loading and digestion is based on our previous work [6,7]. Pressurized nitrogen gas was used to pump the protein samples through the columns at an approximate flow rate of $10 \mu \mathrm{L} / \mathrm{min}$. Each $100 \mu \mathrm{L}$ sample was pumped through the column a total of three times. The column was then washed with $100 \mu \mathrm{L}$ of water. The BSA and lysozyme samples were treated with DL-dithiothreitol (DTT) and iodoacetamide in order to break disulfide bonds prior to loading on the column, using standard protocols. The adsorbed protein was digested by flowing a $10 \mu \mathrm{L}$ solution of $31 \mathrm{ng} / \mu \mathrm{L}$ trypsin in $50 \mathrm{mM}$ $\mathrm{NH}_{4} \mathrm{HCO}_{3}$ through the column. A small volume of enzyme solution was left in the column to prevent the beads from drying. The column was incubated for 30 min at $37^{\circ} \mathrm{C}$, after which the column was eluted with 3 $\mu \mathrm{L}$ of $50 \%$ acetonitrile/water with $0.1 \%$ TFA. Each column was used once and then discarded.

\section{HPLC Separations and Fractionation}

Peptides were separated by HPLC on an Agilent Series 1100 chromatographic system (Agilent Technologies, Palo Alto, CA) using a Vydac n-octylsilica $\left(\mathrm{C}_{8}\right)$ column (Heseria, CA) with dimensions of $250 \times 4.6 \mathrm{~mm}$. Gradient elution was performed using $0.02 \%$ (vol/vol) TFA in water (buffer A) and $0.02 \%$ (vol/vol) TFA in acetonitrile (buffer B). For on-line mass spectrometric detection, $0.5 \%$ acetic acid was used in place of TFA. The gradient used was as follows: hold B at $2 \%$ for 5 min, then increase from 2 to $50 \% \mathrm{~B}$ over $48 \mathrm{~min}$. The flow rate was set at $1 \mathrm{~mL} / \mathrm{min}$. For separation of the adsorbed cytochrome $c$ digests, approximately $25 \%$ of the total sample was injected on the column. For the solution phase digest, $10 \mu \mathrm{L}$ of the sample, equivalent to $8.3 \mu \mathrm{g}$ of cytochrome $c$, was injected on the column. UV chromatograms were recorded at $210 \mathrm{~nm}$. For off-line analysis of the chromatographic separation by MALDI, the effluent was collected in vials at one min intervals with an automated fraction collector. The $1 \mathrm{~mL}$ fractions were concentrated to approximately $50 \mu \mathrm{L}$ by solvent evaporation. The concentrated samples were then analyzed by MALDI-TOF MS.

\section{Mass Spectrometry}

For MALDI analysis, the matrix $\alpha$-cyano-4-hydroxycinnamic acid (HCCA) was used. Prior to use, the HCCA was purified by recrystallization from ethanol. A twolayer deposition method, previously reported by our group, was used to prepare the samples [30]. On-probe washing was performed by placing a $1 \mu \mathrm{L}$ droplet of water on the dried sample spot and blowing off the water with air after a few seconds. The MALDI spectra for the in-column digests were collected on a linear time-lag focusing MALDI time-of-flight mass spectrometer, which was constructed at the University of Alberta and has been described in detail elsewhere [31]. The fractions from the HPLC separation were recorded using a Bruker Reflex III MALDI time-of-flight system (Bremen/Leipzig, Germany). All spectra are the results of signal averaging of between 100 and 200 shots. Data processing was performed with the IGOR Pro software package (Wavemetrics Inc., Lake Oswego, OR).

On-line liquid chromatography/electrospray ionization mass spectrometry (LC/ESI-MS) analysis was performed on a Finnigan $\mathrm{LCQ}^{\text {deca }}$ ion trap mass spectrometer (Finnigan, San Jose, CA). The effluent from the column was split, allowing approximately $20 \mu \mathrm{L} / \mathrm{min}$ to flow to the ion trap for MS analysis.

\section{Results and Discussion}

\section{HPLC Separation with UV Detection of Peptide Fragments}

Cytochrome $c$ was chosen as a model protein to study how the digestion efficiency is affected by adsorption of the protein to a hydrophobic support. This small, hydrophilic protein is readily digested by the enzyme trypsin, producing peptides that are easily separated by HPLC as well as detected by mass spectrometry. Cytochrome $c$ was subjected to tryptic digestion following adsorption to $\mathrm{R} 2$ or $\mathrm{C}_{18}$ beads using the procedure described in the experimental section. For comparative purposes, the protein was also digested with trypsin using a traditional solution-phase digestion procedure. The resulting digestion products were separated by 

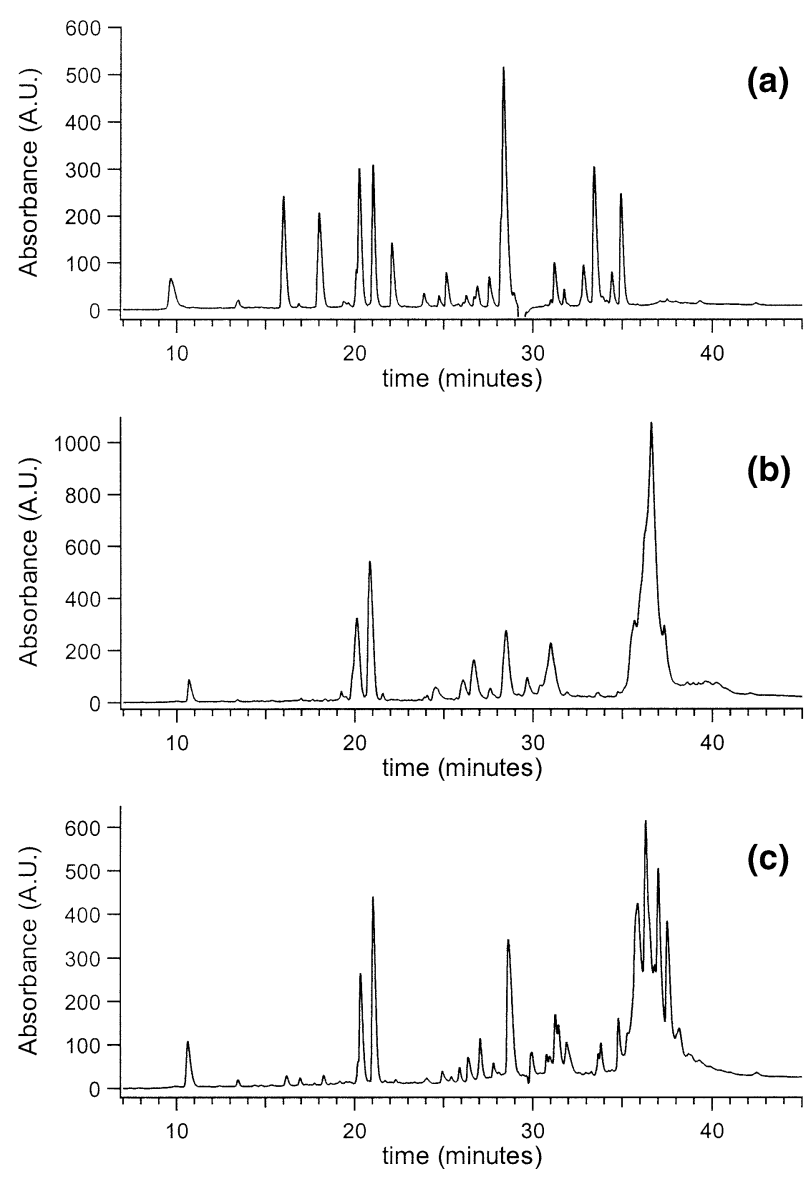

Figure 1. UV chromatograms for the HPLC separations of peptide fragments from the digestion of cytochrome $c$ : (a) in solution, (b) on $\mathrm{C}_{18}$ silica beads, and (c) on polymeric R2 beads.

HPLC and the corresponding UV chromatograms are displayed in Figure 1.

Figure 1a displays the UV chromatogram for the peptide fragments of the solution digest of cytochrome $c$. The UV chromatograms for the surface-bound digestions on $\mathrm{C}_{18}$ and $\mathrm{R} 2$ beads are presented in Figure $1 \mathrm{~b}$ and $c$, respectively. When compared to the UV chromatogram from the solution digest, it is apparent that the adsorption of cytochrome $c$ to these surfaces alters the digestion process. In particular, the solution digest reveals various peaks early in the separation having strong signal intensities that display only low intensities in the surface digests. Also, the two surface digests (Figure $1 \mathrm{~b}$ and $\mathrm{c}$ ) reveal intense peaks between 35 and $40 \mathrm{~min}$, which are essentially absent in the chromatogram of the solution digest (Figure 1a). These results lead to the conclusion that the tryptic digestion of cytochrome $c$ adsorbed to a surface produces an increased proportion of larger, more incompletely digested peptide fragments, compared to a solution digestion of the same protein. We note that increasing digestion times under the experimental conditions used for surface digestion as well as solution digestion did not result in any more complete digestion. This was evident in a series of experiments where digestions were carried out in varying time periods (from $10 \mathrm{~min}$ to $24 \mathrm{~h}$ ) and the resulting digests were analyzed by both UV chromatography and MALDI MS. No apparent changes in UV chromatograms and MALDI spectra were observed (data not shown). Also, these differences cannot be attributed to individual peptides being irreversibly bound, or lost from the support. In a experiment that followed, it was found that when the digestion products of a solution digest of cytochrome $c$ were loaded and subsequently eluted from the bead surface, no apparent changes were observed in the UV trace compared to the one originally obtained (Figure 1a).

A comparison of the chromatograms from the surface-bound digests of cytochrome $c$ on $\mathrm{C}_{18}$ and on R2 beads (Figure $1 \mathrm{~b}$ and $\mathrm{c}$ ) reveals a closer resemblance. Compared to the UV trace of the solution digest, these two traces display many peaks at similar retention times having similar relative peak intensities. This therefore demonstrates that the relative abundances of many of the peptide fragments in each digest are somewhat similar. Some notable differences are observed between the UV chromatograms from Figure $1 \mathrm{~b}$ and c. For example, Figure 1c (R2 beads) reveals a slightly higher relative amount of early eluting peptides than that of Figure $1 \mathrm{~b}\left(\mathrm{C}_{18}\right.$ beads). Also, the relative intensities of the partly resolved peaks between 35 and $40 \mathrm{~min}$ in the UV trace are noticeably different in these two traces. These results therefore indicate that for these two different supports, the type of surface has only a minor influence on the digestion process for surfacebound proteins. It should be noted that in conducting a comparison of digests of a protein on various hydrophobic surfaces the conditions for digestion were optimized according to each surface used. As mentioned in our previous work [6], improved digestion can be achieved as the bead surface becomes increasingly saturated with protein. The initial experiments involving the comparison of $\mathrm{R} 2$ and $\mathrm{C}_{18}$ surfaces by HPLC were therefore conducted under completely saturated digestion condition in which the maximal amount of protein was bound to the bead surface prior to digestion. Using less than saturated condition will create additional variables in comparing the effect of surface property on digestion. For example, a non-saturated surface can adsorb and/or denature trypsin, which leads to a less than optimal digestion process such as impeded enzyme activity and increased trypsin autolysis [6]. Since the surface area and protein adsorptivity are different for different beads (see below), a fixed amount of protein cannot be applied for adsorption onto all beads, as this would result in different protein coverage on different surfaces. Thus, experiments conducted under saturated surface coverage conditions provide the best assessment on the influence of the surface characteristics on trypsin digestion.

To gauge the amount of protein adsorbed on each type of bead surface, cytochrome $c$ was loaded on 7.5 $\mathrm{mg}$ of beads, as described in the Experimental section. Subsequently, the undigested protein was eluted from 
the bead surface with $75 \%$ acetonitrile/ $0.1 \%$ TFA, the acetonitrile was evaporated by SpeedVac, and the protein was quantified using the Bradford Protein Assay. It was found that, under the conditions used in this work, the amount of cytochrome $c$ adsorbed to the R2 surface was $1.1 \mathrm{mg}$, and $1.9 \mathrm{mg}$ for the $\mathrm{C}_{18}$ surface. It was also found that $1.5 \mathrm{mg}$ and $2.3 \mathrm{mg}$ of cytochrome $c$ adsorbed to $C_{4}$ and $C_{8}$ silica beads, respectively. It is clear that different amounts of proteins are adsorbed on different beads. However, these protein amounts represent the saturation of each bead surface. We also note that MALDI analysis of the digestion products revealed a very weak cytochrome $c$ peak, indicating that a small amount of intact cytochrome $c$ still remains after digestion. Since MALDI is not quantitative, the exact amount of the intact protein cannot be determined. No attempt was made to quantify the intact protein by ESI MS, since ion suppression of protein signals in the presence of large amount of peptides is severe and reversedphase LC separation of proteins from digested peptides is difficult. The presence of undigested cytochrome $c$ in the beads may be attributed to those adsorbed on certain areas of the beads that are not accessible by trypsin. Nevertheless, under the saturated digestion conditions, the UV traces can be readily reproduced and do not change significantly as the digestion time varies from $10 \mathrm{~min}$ to $24 \mathrm{~h}$. While the UV chromatograms shown in Figure 1 provide some quantitative comparison of the digestion products and illustrate that the overall digestion efficiency on $\mathrm{a}_{18}$ or an $\mathrm{R} 2$ surface, although comparable between each surface, is clearly different than a solution digestion of the same protein, these results do not provide information on the identities of these digestion products. In the following sections, we present the results from MS analysis of the digestion products to compare the number and type of peptide fragments generated by the tryptic digests.

\section{MS Detection of Solution and Surface-Bound Protein Digests}

Because of the need to survey as many digested peptides as possible to provide a better amino acid sequence coverage of the protein, three modes of MS detection were carried out for analyzing the products of protein digests, namely LC/ESI, LC/off-line MALDI, and direct MALDI, as described in the experimental section. Peptide fragments of cytochrome $c$ observed under these three detection methods were recorded and the results are summarized in Figures 2, 3, and 4. Figure 2 displays the peptides observed from the solution digest of cytochrome $c$, while Figures 3 and 4 list the peptide fragments detected from the $C_{18}$ and $R 2$ bead digestions, respectively. The first column in these figures lists the predicted cleavage sites from tryptic digestion of cytochrome $c$. The peptides detected by either MALDI or ESI MS are organized according to the number of missed cleavages they contain.

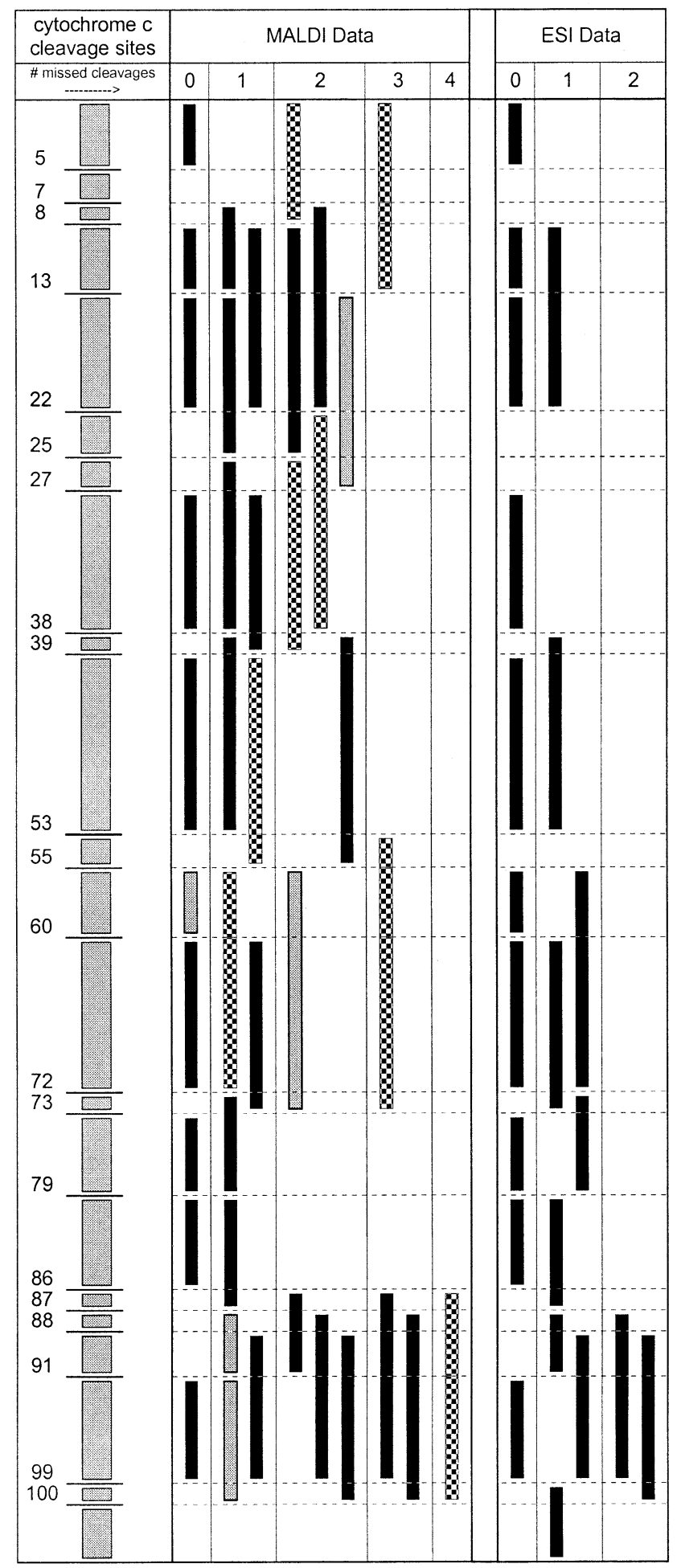

Figure 2. Tryptic peptides detected from the digest of cytochrome $c$ in solution by using MALDI and ESI-MS. The fragments observed exclusively in the direct MALDI analysis are indicated with a gray bar, while those exclusive to LC/off-line MALDI are indicated with a checkered bar. Fragments commonly observed in each MALDI analysis method are indicated with a black bar.

As Figure 2 shows, under the conditions used, a solution digestion of cytochrome $c$ results in a partial digest of the protein, since many incompletely digested 


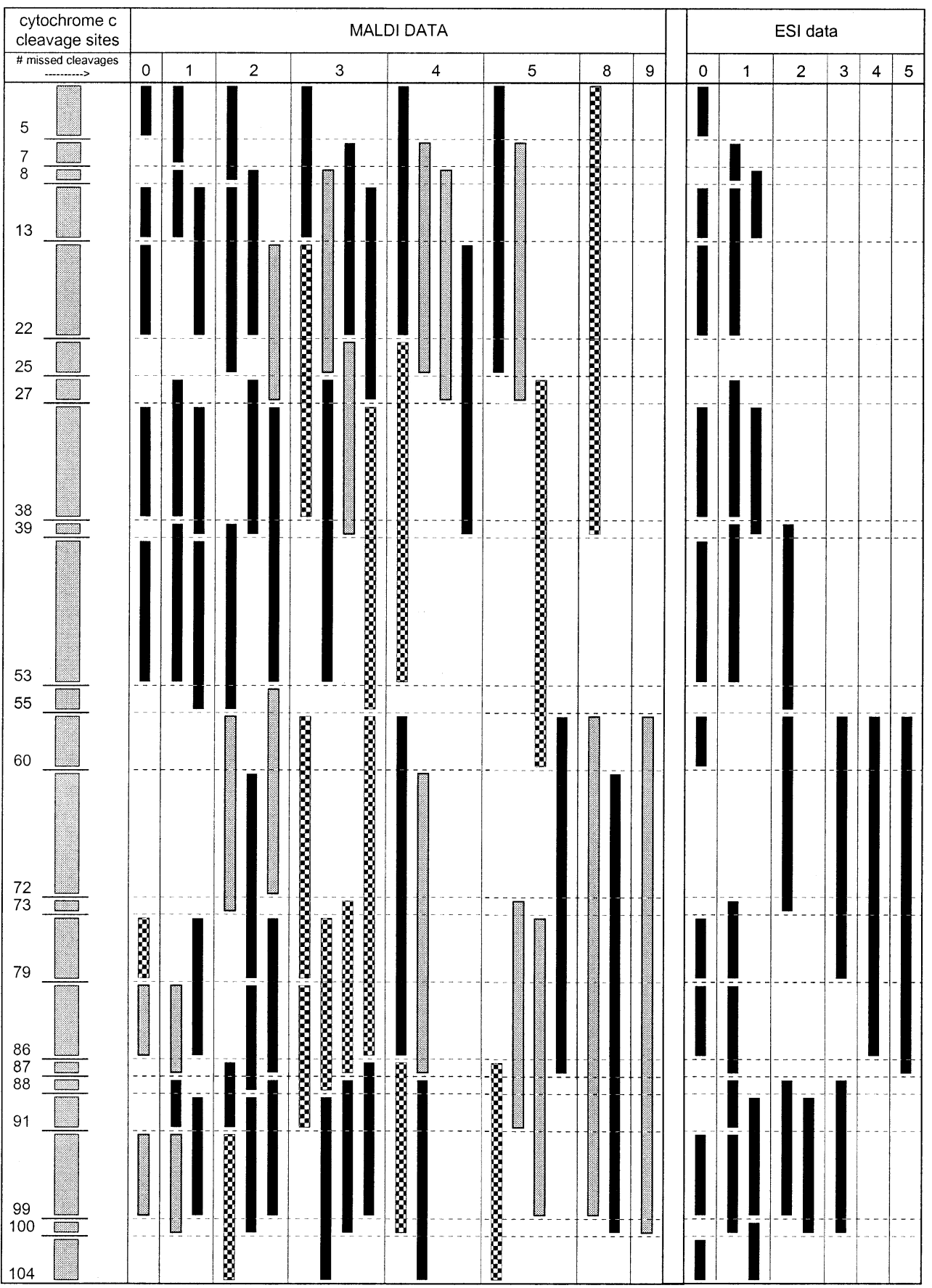

Figure 3. Tryptic peptides detected from the digest of cytochrome $c$ bound to the $C_{18}$ surface by using MALDI and ESI-MS. The fragments observed exclusively in the direct MALDI analysis are indicated with a gray bar, while those exclusive to LC/off-line MALDI are indicated with a checkered bar. Fragments commonly observed in each MALDI analysis method are indicated with a black bar.

peptide fragments were detected. The partial digestion of cytochrome $c$ results in a total of 41 unique peptides observed by MALDI and ESI MS analysis. It is noted that a more complete analysis of the generated peptide fragments is obtained by incorporating all three MS detection schemes since some peptides were exclusively observed in each of the three detection methods. It is likely that additional peptide fragments remained undetected. In particular, short peptide fragments (spanning from 1 to 4 amino acid residues), are difficult to detect by MALDI MS or ESI MS owing to their low molecular weight or inability to retain on a reversed-phase separation column. Nonetheless, the combination of the three MS detection schemes resulted in $100 \%$ sequence coverage for cytochrome $c$. Also, from the peptide fragments detected as shown in Figure 2, all possible tryptic digestion sites of cytochrome $c$ were cleaved and some fragments containing missed cleavage were detected. 


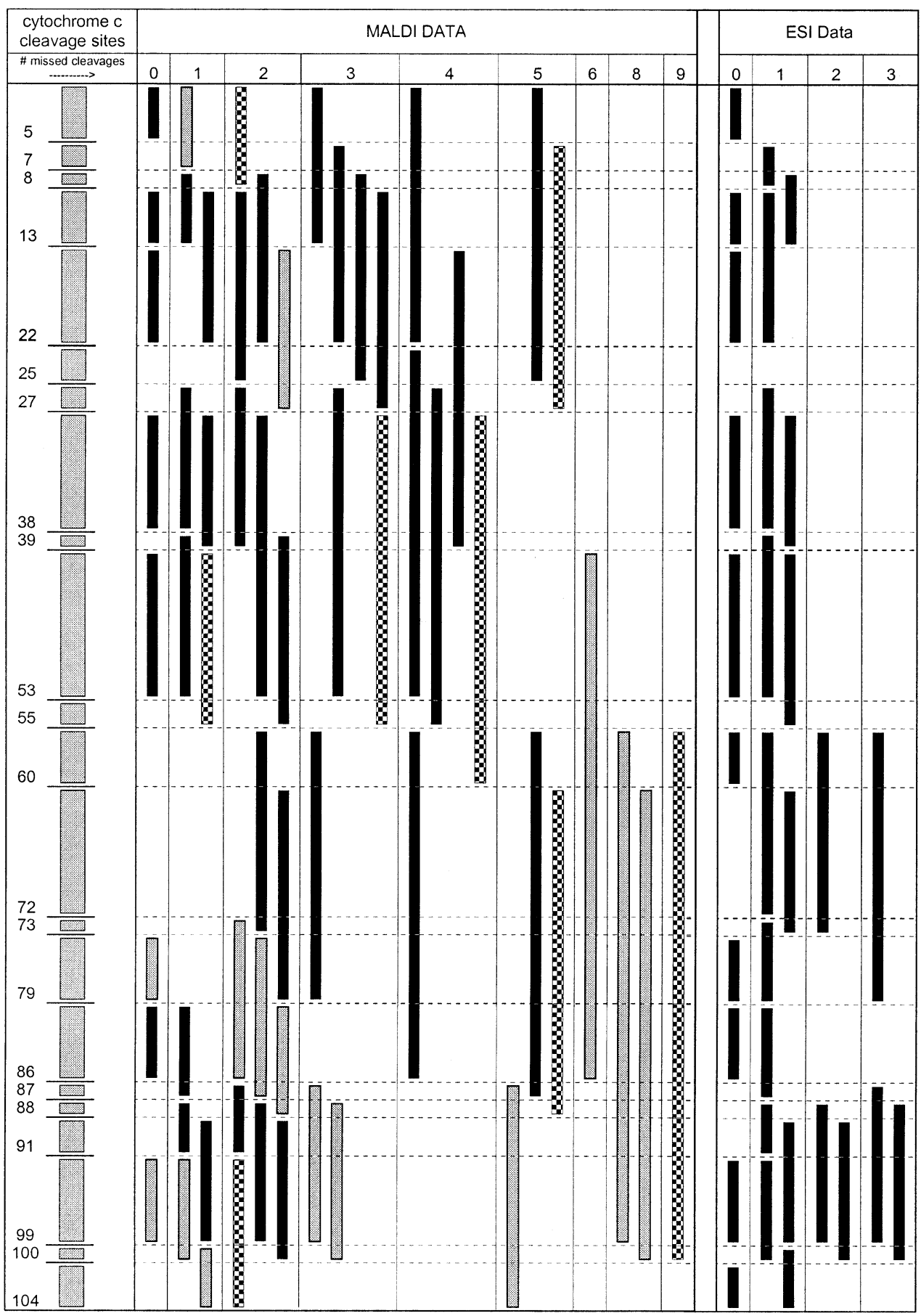

Figure 4. Tryptic peptides detected from the digest of cytochrome $c$ bound to the R2 surface by using MALDI and ESI-MS. The fragments observed exclusively in the direct MALDI analysis are indicated with a gray bar, while those exclusive to LC/off-line MALDI are indicated with a checkered bar. Fragments commonly observed in each MALDI analysis method are indicated with a black bar.

Comparing the solution digest (Figure 2) to the digests of cytochrome $c$ bound to $\mathrm{C}_{18}$ and $\mathrm{R} 2$ beads (Figures 3 and 4), it is obvious that bead digestions generates a larger number of detectable peptide fragment. A total of 66 unique peptide fragments were detected from the $\mathrm{R} 2$ bead digest, while 77 unique peptide fragments were observed from the $C_{18}$ bead digest. This is attributed to the fact that the degree of cleavage for each site in the bead digestion is lower than in the solution digestion. Large peptide fragments containing as many as nine missed cleavages were observed from the bead digests. Most of the larger fragments from the bead digests (having three or more missed cleavages) were not detected from the solution digest. On the other hand, some of the peptides detected in the solution digest having no, or only one 

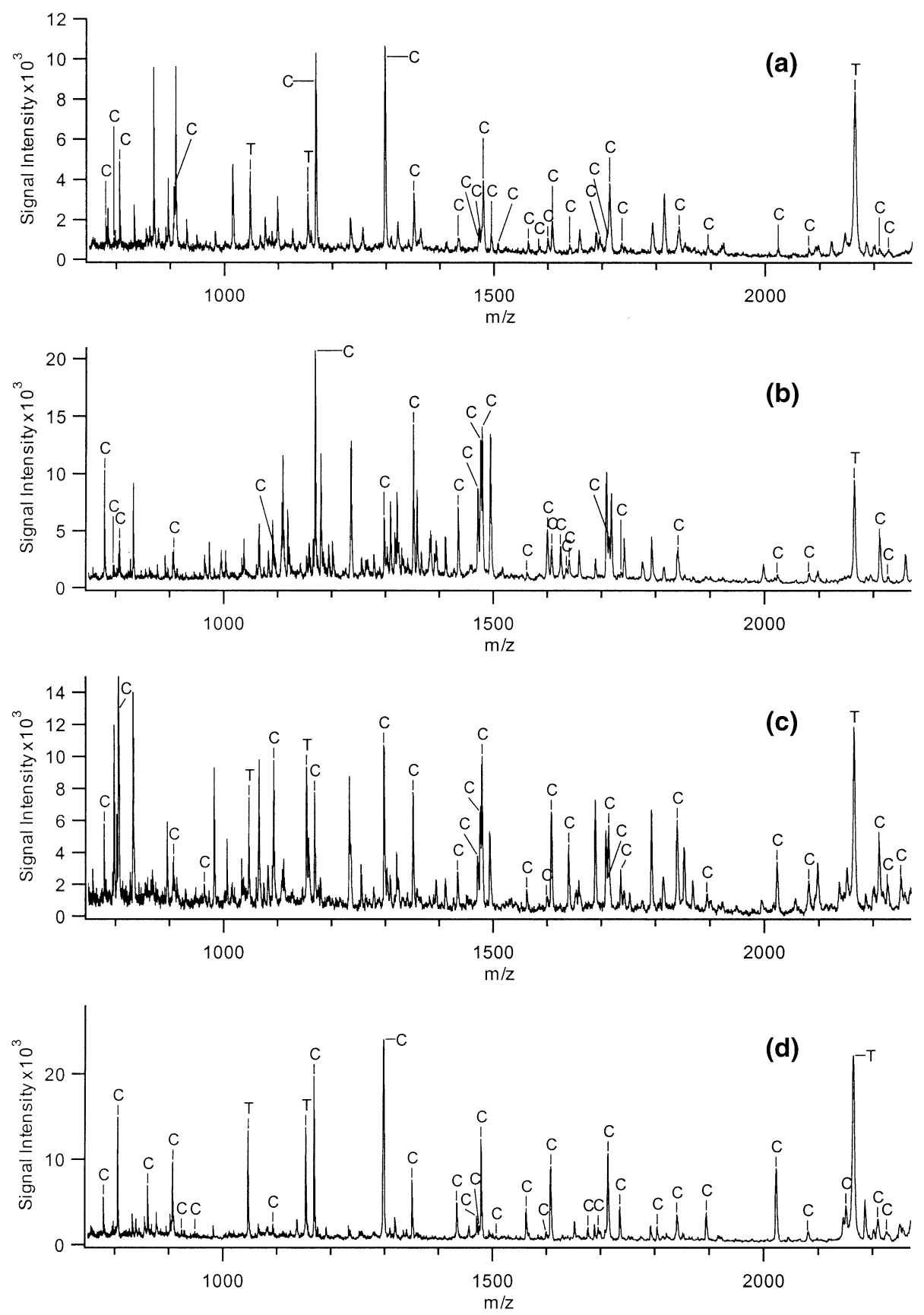

Figure 5. MALDI spectra showing the in-column digestion of 100-nM cytochrome $c$, where the column was packed with (a) Vydac $\mathrm{C}_{18},(\mathbf{b}) \mathrm{C}_{8},(\mathbf{c}) \mathrm{C}_{4}$, and (d) Poros $\mathrm{R} 2$ beads. In the spectra, the label " $\mathrm{C}$ " refers to peptide fragments of cytochrome $c$, and " $\mathrm{T}$ " refers to peptide fragments resulting from trypsin autolysis.

missed cleavage, were not detected in the bead digests. In particular, the results of Figures 3 and 4 reveal a gap in the amino acid sequence between residues 56 to 73 in the MALDI detected peptides with none or one missed cleavage. Attributed to increased detection sensitivity of lower molecular weight peptides, the ESI results reveal a portion of this sequence (i.e., residues from 55 to 66 ) in the $C_{18}$ digest, but again did not detect the completely digested fragment that spans residues 61 to 72 on either surface. Also, a greater number of peptides having an increased number of missed cleavages were observed by ESI, as well as by MALDI, covering this region of the protein. This therefore indicates that the degree of digestion at this portion of the molecule is significantly reduced by adsorption to the bead surface. Based on the significant number of peptides detected having a greater proportion of missed cleavage sites ( $>4$ per fragment), it can be concluded that the adsorption of cytochrome $c$ to $\mathrm{R} 2$ or $\mathrm{C}_{18}$ beads results 
in an overall reduction in digestion efficiency, which is more pronounced at certain regions of cytochrome c.

We note that the combination of the three detection schemes used to analyze the digestion products provides a more detailed investigation on the subtle differences between surface- and solution-phased digests. In particular, analysis by LC/ESI alone would not have revealed most of the larger peptides that were detected by MALDI and LC/MALDI, which constitute the greatest observed differences between the surface and solution digests.

Although less complete digestion is observed as cytochrome $c$ is adsorbed to a solid support, all cleavage sites of cytochrome $c$ were still digested to some degree. Therefore, it can be concluded that protein adsorption does not completely block the digestion of any individual digestion site of this protein. The data shown in Figures 2-4 also suggest that the effect of support type on the extent of digestion is relatively small compared to the differences resulting between a solution digestion and a digest of a surface-bound protein, which is in agreement with the data from the UV chromatograms.

It should be noted that the observation of bead digestion producing a peptide map containing a much wider range of peptide fragments compared to solution digestion is significant for protein identification and characterization. Just as various enzymes can be used to generate unique peptide fragments from a protein, this work shows that the adsorption of a protein to a surface can generate unique peptides from a digestion with the same enzyme. Peptide fragments containing a higher degree of missed cleavage sites are useful to confirm the sequence of a segment of protein observed from smaller peptide fragments. In other cases, where cleavage sites are closely spaced within a given protein, segments of a given protein are sometimes only detected with MALDI or ESI as portions of larger fragments with increased missed cleavages. This is particularly useful where the detection of all residues is required, as in the case of amino acid sequencing or the localization of posttranslational modifications.

\section{In-Column Digestion of Proteins on Various Supports}

As it was demonstrated recently [3], microbeads packed in a microcolumn can be used for protein capture and digestion. Protein capture requires a strong binding of protein to the bead surface, hence favors the use of more hydrophobic surfaces such as $C_{18}$. However, strong binding may adversely affect the digestion process. The effects of various supports on digestion of proteins captured from a dilute solution are therefore investigated. Figure 5 shows the MALDI spectra obtained from the digests of cytochrome $c$ adsorbed to four commonly used chromatographic beads. Solutions consisting of $100 \mu \mathrm{L}$ of $100 \mathrm{nM}$ protein were used to load the microcolumns. The microcolumns were packed with Poros R2 beads, $\mathrm{C}_{18}$ bonded-phase silica beads, $\mathrm{C}_{8}$ beads, or $C_{4}$ beads. The results shown in Figure 5 represent the digestion products that were obtained under optimized in-column digestion conditions for the dilute protein solutions used. As seen in Figure 5, many peaks corresponding to peptide fragments of cytochrome $c$ are visible in the MALDI spectra (these peaks are labeled " $\mathrm{C}$ "). Also, other peaks were detected, including trypsin autolysis fragments (labeled " $\mathrm{T}$ " in the figure) as well as a few commonly observed matrix clusters of HCCA. In addition, several unidentified peaks (i.e., most unlabeled peaks in the figure) are visible in the spectra displayed in Figure 5. In particular, an increased number of unknown peaks are observed in the MALDI spectrum as the support is varied from $\mathrm{R} 2$ to $\mathrm{C}_{18}$ to $\mathrm{C}_{8}$ to $\mathrm{C}_{4}$. It is suspected that these peaks may also be the fragments of cytochrome $c$, arising from non-specific tryptic cleavage of the protein while adsorbed to the various supports. These unidentified peaks, along with other differences, such as signal intensities, contribute to the observed differences in the MALDI spectra for digests on the various bead supports.

Although the spectra shown in Figure 5 exhibit several differences, the information conveyed by the MALDI spectra for each surface digest is very similar. This is more clearly shown by the data presented in Table 1, which lists the peptide fragments detected from each of the four column digestions. From this table, we see that the obtained peptide mass maps from the cytochrome $c$ digests on each type of support are very similar. A similar number of peptide fragments were detected from the digests on each surface type, several of which being common to all four surfaces. Of the peptide fragments that were not commonly observed in each digest, most were of low signal intensity. These results indicate that the choice of surface employed (i.e., $\mathrm{R} 2, \mathrm{C}_{18}, \mathrm{C}_{8}$, or $\mathrm{C}_{4}$ ) has little effect on the outcome of the obtained peptide fragments from MS detection.

These results were further confirmed by digestion of various proteins on each of the four support types. A microcolumn digestion of BSA (using $100 \mu \mathrm{L}$ of $100 \mathrm{nM}$ protein to load the column) also revealed similar results with each of the four surfaces. These results are summarized in Table 2. In this case, between 32 and 36 peptides were detected from each individual digest, with 26 peptide fragments being common to each of the four surfaces. Again, the peaks detected that were unique to a single support type were only weakly observed in the MALDI spectra. Similarly, microcolumn digests of $100 \mathrm{nM}$ lysozyme on each of these four surfaces were essentially identical in terms of the number of peaks, as seen in Table 2 . In this case, between 14 and 17 peaks were detected from each individual digest, and of these 12 peptides were commonly observed in each of the four digests. The 12 commonly observed peptides represent $73 \%$ sequence coverage. As high as 
Table 1. Tryptic peptides detected from the digests of cytochrome $c$ bound to various surfaces

\begin{tabular}{|c|c|c|c|c|c|c|}
\hline \multirow[b]{2}{*}{ Peak \# } & \multirow{2}{*}{$\begin{array}{l}\text { Amino acid } \\
\text { residue }\end{array}$} & \multirow{2}{*}{$\begin{array}{l}\text { Peak } \\
\text { mass }\end{array}$} & \multicolumn{4}{|c|}{ Type of hydrophobic surface } \\
\hline & & & $\mathrm{C}_{18}$ & $\mathrm{C}_{8}$ & $\mathrm{C}_{4}$ & $\mathrm{R} 2$ \\
\hline 1 & $1-8$ & 860.5 & & & & $x$ \\
\hline 2 & $1-13$ & 1475.9 & $x^{a}$ & $x$ & $x$ & $x$ \\
\hline 3 & $6-13$ & 947.6 & & & & $x$ \\
\hline 4 & $9-22$ & 2250.8 & & & $x$ & \\
\hline 5 & $14-22$ & 1635.4 & & $x$ & & \\
\hline 6 & $23-38$ & 1675.9 & & & & $x$ \\
\hline 7 & $23-39$ & 1804.0 & & & & $x$ \\
\hline 8 & $26-39$ & 1561.9 & $x$ & $x$ & $x$ & $x$ \\
\hline 9 & $26-38$ & 1433.8 & $x$ & $x$ & $x$ & $x$ \\
\hline 10 & $28-38$ & 1168.6 & $x$ & $x$ & $x$ & $x$ \\
\hline 11 & $28-39$ & 1296.7 & $x$ & $x$ & $x$ & $x$ \\
\hline 12 & $39-53$ & 1598.8 & $x$ & $x$ & $x$ & $x$ \\
\hline 13 & $39-55$ & 1840.9 & $x$ & $x$ & $x$ & $x$ \\
\hline 14 & $40-53$ & 1470.7 & $x$ & $x$ & $x$ & $x$ \\
\hline 15 & $40-55$ & 1712.8 & $x$ & $x$ & $x$ & $x$ \\
\hline 16 & $56-72$ & 2081.0 & $x$ & $x$ & $x$ & $x$ \\
\hline 17 & $56-73$ & 2209.3 & $x$ & $x$ & $x$ & $x$ \\
\hline 18 & $61-72$ & 1495.7 & $x$ & & & \\
\hline 19 & $61-73$ & 1623.8 & & $x$ & & \\
\hline 20 & $73-79$ & 806.5 & $x$ & $x$ & $x$ & $x$ \\
\hline 21 & $74-88$ & 1695.0 & $x$ & & & $x$ \\
\hline 22 & $80-86$ & 779.4 & $x$ & $x$ & $x$ & $x$ \\
\hline 23 & $80-87$ & 907.5 & $x$ & $x$ & $x$ & $x$ \\
\hline 24 & $87-100$ & 1735.0 & $x$ & $x$ & $x$ & $x$ \\
\hline 25 & 87-104 & 2150.2 & & & & $\mathrm{x}$ \\
\hline 26 & $88-99 / 89-100$ & 1478.8 & $x$ & $x$ & $x$ & $x$ \\
\hline 27 & $87-99 / 88-100$ & 1606.9 & $x$ & $x$ & $x$ & $x$ \\
\hline 28 & 88-104 & 2022.1 & $x$ & $x$ & $x$ & $x$ \\
\hline 29 & 89-99 & 1350.7 & $x$ & $x$ & $x$ & $x$ \\
\hline 30 & 89-104 & 1894.0 & $x$ & & $x$ & $x$ \\
\hline 31 & $92-99$ & 964.5 & & & $x$ & \\
\hline 32 & $92-100$ & 1092.6 & & $x$ & $x$ & $x$ \\
\hline 33 & $92-104$ & 1507.8 & $x$ & & & $x$ \\
\hline Total number of peaks & & & 23 & 22 & 23 & 28 \\
\hline Sequence coverage & & & $89 \%$ & $97 \%$ & $97 \%$ & $91 \%$ \\
\hline
\end{tabular}

${ }^{a} \mathrm{An}$ ' $\mathrm{x}$ ' indicates that the peak was observed in the MALDI MS analysis of the digestion products.

$100 \%$ sequence coverage could be obtained from an individual digest, as some larger individual fragments can contribute to a somewhat greater difference in the sequence coverage.

We note that we have not investigated the effect of surface chemistry on digestion of very hydrophobic surface-bound proteins. It was shown earlier [6] that this type of protein requires chemical cleavage prior to trypsin digestion.

\section{Effects of Bead Construction and Pore Size on Digestion}

We have explored the possible effects of pore size of the beads on protein digestion. Proteins may enter pores of the beads, making them less accessible to trypsin. To address this, we compared the peptide maps obtained from the digestion of cytochrome $c$ on various polystyrene divinylbenzene surfaces, each having differences

Table 2. Summary of digestion products detected by MALDI MS resulting from in-column digests of 100-nM lysozyme and 100-nM BSA using four hydrophobic supports to pack the columns

\begin{tabular}{|c|c|c|c|c|c|c|c|c|}
\hline & \multicolumn{4}{|c|}{ lysozyme } & \multicolumn{4}{|c|}{ BSA } \\
\hline & $\mathrm{C}_{18}$ & $\mathrm{C}_{8}$ & $\mathrm{C}_{4}$ & $\mathrm{R} 2$ & $\mathrm{C}_{18}$ & $\mathrm{C}_{8}$ & $\mathrm{C}_{4}$ & $\mathrm{R} 2$ \\
\hline Number peptides detected & 15 & 14 & 14 & 17 & 32 & 36 & 36 & 36 \\
\hline Sequence coverage & $73 \%$ & $79 \%$ & $99 \%$ & $100 \%$ & $38 \%$ & $36 \%$ & $47 \%$ & $48 \%$ \\
\hline Common peptides & \multicolumn{4}{|c|}{12 common peptides (73\% coverage) } & \multicolumn{4}{|c|}{26 common peptides (31\% coverage) } \\
\hline
\end{tabular}


in pore sizes. The four different beads used in this study included PRP-3 beads (mean pore size $300 \AA$, 12-20 $\mu \mathrm{m}$ diameter), PRP- 1 beads (mean pore size $100 \AA$, 12-20 $\mu \mathrm{m}$ diameter), and PRP-Infinity beads (non-porous, 4 $\mu \mathrm{m}$ diameter), as well as R2 beads (having throughpores of $6000-8000 \AA$, and diffusive pores of $800-1500$ $\AA$, bead diameter $20 \mu \mathrm{m}$ ). The obtained MALDI spectra from digests of cytochrome $c$, lysozyme, and BSA adsorbed on these beads were all similar in terms of the number and type of peptides detected (data not shown). In particular, samples digested on the PRP-Infinity beads, which do not have any pores, did not improve the quality of the MALDI spectrum, compared to samples digested on beads of varying pore sizes. Therefore, it is concluded that pore size does not have a significant effect on the digestion efficiency of an adsorbed protein.

\section{Conclusions}

Protein samples that are soluble in aqueous solution can be digested with trypsin while adsorbed on hydrophobic surfaces, namely reversed-phase chromatography beads. UV chromatographic analysis of the protein digests clearly indicates that the overall digestion process is altered in going from a solution digest to a surface-bound digestion, however, only minor differences can be observed as a result of varying the surface from $\mathrm{R} 2$ to $\mathrm{C}_{18}$ beads. Mass spectrometric analysis specifically shows the difference in the type of peptides generated from these two methods (solution versus surface-bound digests). We demonstrate that using a combination of direct MALDI, LC/off-line MALDI, and LC/ESI MS analysis, instead of using a single MS detection technique by itself, subtle changes in protein digestion characteristics can be revealed. It is shown that a greater number of peptides containing missed cleavage sites are detected in the surface digestion.

We have also demonstrated that peptide mass maps obtained by direct MALDI analysis show similar levels of protein sequence coverage for the digests of proteins bound to $\mathrm{C}_{18}, \mathrm{C}_{8}, \mathrm{C}_{4}$, and $\mathrm{R} 2$ beads. In addition, the pore size of the beads does not have a significant effect on the digestion characteristics of an adsorbed protein. Thus, for protein identification by peptide mass mapping using direct MALDI analysis of the surface-bound protein digest, any one of the hydrophobic surfaces examined herein can be used. The choice of the microbead surface is therefore mainly dependent on the efficiency of protein retention, which can be optimized for different applications. For example, $\mathrm{C}_{18}$ beads should provide a better retention for many proteins and thus they are the preferred media for routine microcolumn digestion experiments.

\section{Acknowledgments}

This work was funded by the Natural Sciences and Engineering Research Council of Canada (NSERC). AD thanks the NSERC for a Graduate Fellowship.

\section{References}

1. Aebersold, R. H.; Leavitt, J.; Saavedra, R. A.; Hood, L. E.; Kent, S. B. Internal Amino Acid Sequence Analysis of Proteins Separated by One- or Two-Dimensional Gel Electrophoresis After in Situ Protease Digestion on Nitrocellulose. Proc. Natl. Acad. Sci. U.S.A. 1987, 84, 6970-6974.

2. Reid, G.; Gan, B. S.; She, Y. M.; Ens, W.; Weinberger, S.; Howard, J. C. Rapid Identification of Probiotic Lactobacillus Biosurfactant Proteins by Protein Chip Tandem Mass Spectrometry Tryptic Peptide Sequencing. Appl. Environ. Microbiology 2002, 68, 977-980.

3. Issaq, H. J.; Veenstra, T. D.; Conrads, T. P.; Felschow, D. The SELDI-TOF MS Approach to Proteomics: Protein Profiling and Biomarker Identification. Biochem. Biophys. Res. Commun. 2002, 292, 587-592.

4. Merchant, M.; Weinberger, S. R. Recent Advancements in Surface-Enhanced Laser Desorption/Ionization Time-ofFlight Mass Spectrometry. Electrophoresis 2000, 21, 1164-1171.

5. Doucette, A.; Craft, D.; Li, L. Protein Concentration and Enzyme Digestion on Microbeads for MALDI-TOF Peptide Mass Mapping of Proteins from Dilute Solutions. Anal. Chem. 2000, 72, 3355-3362.

6. Craft, D.; Doucette, A.; Li, L. Microcolumn Capture and Digestion of Proteins Combined with Mass Spectrometry for Protein Identification. J. Proteome Research 2002, 1, 537-547.

7. Craft, D.; Doucette, A.; Li, L. In-Column Protein Concentration, Sample Clean Up, and Enzyme Digestion of Dilute Proteins for MALDI-TOF Peptide Mass Mapping of Proteins. Proceedings of the 48th ASMS Conference on Mass Spectrometry and Allied Topics; Long Beach, CA, June, 2000; p 1429.

8. Vestling, M. M.; Fenselau, C. Poly(vinylidene difluoride) Membranes as the Interface Between Laser Desorption Mass Spectrometry, Gel Electrophoresis, and in Situ Proteolysis. Anal. Chem. 1994, 66, 471-477.

9. Bienvenut, W. V.; Sanchez, J. C.; Karmime, A.; Rouge, V.; Rose, K.; Binz, P.-A.; Hochstrasser, D. F. Toward a Clinical Molecular Scanner for Proteome Research: Parallel Protein Chemical Processing Before and During Western Blot. Anal. Chem. 1999, 71, 4800-4807.

10. Courchesne, P. L.; Luethy, R.; Patterson, S. D. Comparison of In-Gel and On-Membrane Digestion Methods at Low to Subpmol Level for Subsequent Peptide and Fragment-Ion Mass Analysis Using Matrix-Assisted Laser-Desorption/Ionization Mass Spectrometry. Electrophoresis 1997, 18, 369-381.

11. Lui, M.; Tempst, P.; Erdjument-Bromage, H. Methodical Analysis of Protein-Nitrocellulose Interactions to Design a Refined Digestion Protocol. Anal. Biochem. 1996, 241, 156-166.

12. Fabris, D.; Vestling, M. M.; Cordero, M. M.; Doroshenko, V. M.; Cotter, R. J.; Fenselau, C. Sequencing Electroblotted Proteins by Tandem Mass Spectrometry. Rapid Comm. Mass Spectrom. 1995, 9, 1051-1055.

13. Vestling, M. M.; Fenselau, C. Surfaces for Interfacing Protein Gel Electrophoresis Directly with Mass Spectrometry. Mass Spectrom. Rev. 1995, 14, 169-178.

14. Schleuder, D.; Hillenkamp, F.; Strupat, K. IR-MALDI Mass Analysis of Electroblotted Proteins Directly from the Membrane: Comparison of Different Membranes, Application to On-Membrane Digestion, and Protein Identification by Database Searching. Anal. Chem. 1999, 71, 3238-3247.

15. McComb, M. E.; Oleschuk, R. D.; Manley, D. M.; Donald, L.; Chow, A.; O'Neil, D. J.; Ens, W.; Standing, K. G.; Perreault, H. Use of a Non-Porous Polyurethane Membrane as a Sample Support for Matrix-Assisted Laser Desorption/Ionization Time-of Flight Mass Spectrometry of Peptides and Proteins. Rapid Comm. Mass Spectrom. 1997, 11, 1716-1722.

16. McComb, M.; Oleschuk, R. D.; Chow, A.; Ens, W.; Standing, K. G.; Perrault, H.; Smith, M. Characterization of Hemoglobin 
Variants by MALDI-TOF MS Using a Polyurethane Membrane as the Sample Support. Anal. Chem. 1998, 70, 5142-5149.

17. Lee, C. H.; McComb, M. E.; Bromirski, M.; Jilkine, A.; Ens, W.; Standing, K. G.; Perrault, H. On-Membrane Digestion of $\beta$-Casein for Determination of Phosphorylation Sites by Matrix-Assisted Laser Desorption/Ionization Quadrupole/Timeof-Flight Mass Spectrometry. Rapid Comm. Mass. Spectrom. 2001, 15, 191-202.

18. Aguilar, M.; Clayton, D. J.; Holt, P.; Kronina, V.; Boysen, R. I.; Purcell, A. W.; Hearn, M. T. W. RP-HPLC Binding Domains of Proteins. Anal. Chem. 1998, 70, 5010-5018.

19. Jemmerson, R.; Paterson, Y. Mapping Epitopes on a Protein Antigen by the Proteolysis of Antigen-Antibody Complexes. Science 1986, 232, 1001-1004.

20. Suckau, D.; Kohl, J.; Karwath, G.; Schneider, K.; Casaretto, M.; Bitter-Suermann, D.; Przybylski, M. Molecular Epitope Identification by Limited Proteolysis of an Immobilized AntigenAntibody Complex and Mass Spectrometric Peptide Mapping. Proc. Natl. Acad. Sci. U.S.A. 1990, 87, 9848-9852.

21. Macht, M.; Fiedler, W.; Kurzinger, K.; Przybylski, M. Mass Spectrometric Mapping of Protein Epitope Structures of Myocardial Infarct Markers Myoglobin and Troponin T. Biochemistry 1996, 35, 15633-15639.

22. Burnens, A.; Demotz, S.; Corradin, G.; Binz, H.; Bosshard, H. Epitope Mapping by Chemical Modification of Free and Antibody-Bound Protein Antigen. Science 1987, 235, 780783.

23. Schreimer, D. C.; Li, L. Combining Avidin-Biotin Chemistry with Matrix-Assisted Laser Desorption/Ionization Mass Spectrometry. Anal. Chem. 1996, 68, 3378-3382.
24. Schreimer, D. C.; Yalcin, T.; Li, L. MALDI Mass Spectrometry Combined with Avidin-Biotin Chemistry for Analysis of Protein Modifications. Anal. Chem. 1998, 70, 1569.

25. Litborn, E.; Emmer, A.; Roeraade, J. Chip Based Nanovials for Tryptic Digest and Capillary Electrophoresis. Anal. Chim. Acta 1999, 401, 11-19.

26. Kosciarz, E.; Vercaigne-Marko, D.; Scellier, N.; Nedjar-Arroume, N.; Guillochon, D. Selectivity Modification of Chymotryptic Hydrolysis of Haemoglobin by Its Adsorption on a Solid Phase. Biotechnol. Appl. Biochem. 1999, 30, 147-153.

27. Vercaigne-Marko, D.; Kosciarz, E.; Nedjar-Arroume, N.; Guillochon, D. Improvement of Staphylococcus aureus-V8-Protease Hydrolysis of Bovine Haemoglobin by its Adsorption on to a Solid Phase in the Presence of SDS: Peptide Mapping and Detention of Two Haemopoietic Peptides. Biotechnol. Appl. Biochem. 2000, 31, 127-134.

28. Gobom, J.; Nordhoff, E.; Ekman, R.; Roepstorff, P. Rapid Micro-Scale Proteolsis of Proteins for MALDI-MS Peptide Mapping Using Immobilized Trypsin. Int. J. Mass Spectrom. Ion. Processes 1997, 169/170, 153-163.

29. Annan, R. S.; McNulty, D. E.; Carr, S. A. High Sensitivity Identification of Proteins from SDS PAGE using In-Gel Digestion and MALDI-PSD. Proceedings of the 44th ASMS Conference on Mass Spectrometry and Allied Topics; Portland, OR, May, 1996; p 702.

30. Dai, Y.; Whittal, R. M.; Li, L. Two-Layer Sample Preparation: A Method for MALDI-MS Analysis of Complex Peptide and Protein Mixtures. Anal. Chem. 1999, 71, 1087-1091.

31. Whittal, R. M.; Li, L. High-Resolution Matrix-Assisted Laser Desorption/Ionization in a Linear Time-of-Flight Mass Spectrometer. Anal. Chem. 1995, 67, 1950-1954. 